\title{
Entre a asfixia e a resistência: \\ a "luta ideológica de movimento" em torno da educação nacional
}

Bruna Maria de Sousa Santos $^{1}$
Washington Silva de Farias

[...] a situação típica da censura traduz exatamente esta asfixia: ela

é a interdição manifesta da circulação do sujeito, pela decisão de um poder de palavra fortemente regulado.

Eni Orlandi, As formas do silêncio.

- não há dominação sem resistência: primeiro prático da luta de classes, que significa que é preciso "ousar se revoltar".

Michel Pêcheux, Semântica e Discurso.

Resumo: Neste artigo, buscamos compreender o funcionamento das políticas de significação dos discursos dos movimentos Escola sem Partido (MESP) e Professores contra o Escola sem Partido (MPCESP), inscritos em uma luta ideológica em torno dos objetos de ensino da educação nacional. Entendemos que o discurso do MESP é orientado pelo que propomos chamar de uma política de asfixia da educação, que produz o efeito de despolitização e cristianização daquilo que pode/deve ser ensinado na escola. Por outro lado, entendemos que o discurso do MPCESP é dirigido a partir de uma política de resistência à asfixia da educação, produzindo choques de deslocamento que reinscrevem o processo de ensino-aprendizagem na ordem do político.

Palavras-Chave: Discurso político-educacional. Políticas de Significação. Escola sem Partido. Professores contra a Escola sem Partido.

\footnotetext{
${ }^{1}$ Mestra em Linguagem e Ensino pela Universidade Federal de Campina Grande.

2 Doutor em Linguística pela Universidade Federal da Paraíba. Professor do Programa de PósGraduação em Linguagem e Ensino da Universidade Federal de Campina Grande.
} 
Abstract: In this article, we seek to understand the functioning of the politics of signification of the discourses of the Partyless School (MPS) and Teachers Against Partyless School (MTAPS) movements, inscribed in an ideological struggle around the teaching objects of the national education. We understand that the discourse of the MPS is guided by what we propose to call a politics of education asphyxiation, which produces the depoliticization and christianization effect of what can/should be taught in school. On the other hand, we understand that MTAPS's discourse is driven by a politics of resistance to the education asphyxiation, producing displacement shocks that reinsert the teaching-learning process in the political order.

Keywords: Political-educational discourse. Politics of signification. Partyless School. Teachers Against Partyless School.

Resumen: En este artículo, buscamos comprender el funcionamiento de las políticas de significación de los discursos de los movimientos Escuela sin Partido (MESP) y Profesores contra lo Escuela sin Partido (MPCESP), inscritos en una lucha ideológica en torno a los objetos de enseñanza de la educación nacional. Entendemos que el discurso del MESP está orientado por lo que proponemos llamar una política de asfixia de la educación, que produce el efecto de despolitización y cristianización de lo que puede/debe ser enseñado en la escuela. Por otro lado, entendemos que el discurso del MPCESP es dirigido a partir de una política de resistencia a la asfixia de la educación, produciendo choques de desplazamiento que reinscriben el proceso de enseñanza-aprendizaje en el orden de lo político.

Palabras clave: Discurso político-educativo. Políticas de Significación. Escuela sin Partido. Profesores contra lo Escuela sin Partido.

\section{Introdução}

Ao refletir sobre os processos de reprodução/transformação das relações de classe, o filósofo francês Michel Pêcheux (1982 [2014]) propôs pensar a noção de lutas ideológicas de movimento, definindo-as como uma série de embates móveis, travados em torno de objetos ideológicos, também chamados de objetos paradoxais, por possuírem a singularidade de serem idênticos e antagônicos consigo mesmos, devido ao seu funcionamento baseado "em relações de força móveis, em mudanças confusas, que levam a concordâncias e oposições extremamente instáveis" (PÊCHEUX, 1982 [2014], p. 115-116). Partindo dessa reflexão, propomos, neste artigo, pensar a educação enquanto objeto paradoxal, tal como definido por Pêcheux, uma vez que esta tem se constituído, historicamente, como uma arena de disputa entre diferentes posições que problematizam o lugar da escola e os limites e propósitos do processo de ensinoaprendizagem. 
No contexto sócio-político contemporâneo, marcado por um crescente discurso conservador (SINGER, 2016), o imaginário sobre a educação brasileira tem sido tensionado a partir de reinvindicações por um ensino "neutro", apartado de questões políticas e ideológicas. Dentre as vozes que clamam pela neutralidade no ensino, está o movimento Escola sem Partido (MESP), que contesta a abordagem de temas como orientação sexual e identidade de gênero na escola, partindo do pressuposto de que tais temas confrontam princípios morais e religiosos das famílias tradicionais brasileiras, ferindo, assim, a laicidade do Estado.

O discurso do MESP obteve grande visibilidade sobretudo a partir do ano de 2014, quando Projetos de Lei (PL), inspirados nas propostas desse movimento, passaram a tramitar na Câmara dos Deputados e em Assembleias Legislativas de todo o país. De modo geral, os PL propõem reorientar os princípios pedagógicos da Lei de Diretrizes e Bases da Educação Nacional (LDB), apagando ou ressignificando parte daqueles que fazem referência às dimensões políticas e sociais do processo de ensinoaprendizagem, a pretexto de garantir, assim, a neutralidade na Educação.

Por meio dos Projetos de Lei e participações em audiências públicas sobre os PL, bem como através de suas páginas virtuais (Facebook e Blog), o MESP dissemina seu discurso, de modo a combater o que seus representantes denominam de doutrinação ideológica “de esquerda”. Marca-se, assim, uma tentativa de controle sobre os sentidos daquilo que pode/deve ser ensinado na escola, sobretudo, em relação às questões de política, gênero e sexualidade.

Com a disseminação do Movimento Escola sem Partido e seus Projetos de Lei, estudantes, professores, entidades e associações do setor educacional passaram a se articular, produzindo um discurso de resistência ao movimento, e dando origem, em 2015, ao coletivo Professores contra o Escola sem Partido (MPCESP). Tal coletivo, articulado ao Movimento Educação Democrática, tem atuado de forma a problematizar o ideal de educação neutra defendida pelo MESP, marcando forte oposição na participação de debates, seminários e audiências públicas referentes aos Projetos de Lei "Escola sem Partido”. 
Emerge, desse modo, um "duelo" pelo objeto paradoxal da educação, que permite observar o funcionamento de um discurso polêmico 3 (ORLANDI, 2013), em que o referente - os objetos de ensino da educação nacional - é disputado pelos interlocutores. Nesse embate de posições, a educação é (re)inscrita em um espaço polêmico, entre a "neutralidade" e a politicidade 4 daquilo que pode/deve ser ensinado na escola. A partir dessa problemática, buscamos, neste artigo, compreender o modo de funcionamento dos discursos do MESP e do MPCESP. Devemos mencionar, no entanto, que os sentidos produzidos pelo MESP e pelo MPCESP, embora antagônicos, não se constituem em relação de antítese, isto é, não são simetricamente opostos, mas estabelecem uma correlação mais complexa em que cada discurso obedece a uma política de significação $0^{5}$ distinta.

Examinando, pois, as políticas de significação dos discursos em questão, observamos que a discursividade do movimento Escola sem Partido funciona a partir de uma política que "dirige" os sentidos por meio do silêncio local (ORLANDI, 1993), isto é, pela censura e imposição de uma direção única para os sujeitos e os sentidos, bloqueando, assim, a heterogeneidade e polissemia no contexto educacional. Nos movemos, então, em direção à hipótese de que o discurso do MESP funciona por meio do que propomos chamar de uma política de asfixia sentidos, dada sua inscrição na ordem do calar.

De modo mais específico, pensamos a política de asfixia como um processo engendrado por uma discursividade autoritária ${ }^{6}$, que procura restringir (sufocar) e controlar os sujeitos e os sentidos em sua relação com o dizível. Esse controle funciona pelo viés da interdição/censura, entendida aqui como fato discursivo que instaura uma produção de sentidos proibidos sobre a educação, delimitando a inscrição dos sujeitos

\footnotetext{
${ }^{3}$ Segundo definição de Orlandi (2013, p. 86), o discurso polêmico é caracterizado como aquele em que "a polissemia é controlada, o referente é disputado pelos interlocutores, e estes se mantêm em presença, numa relação tensa de disputa pelos sentidos".

${ }^{4}$ Este termo é definido por Freire (1996) como sendo o traço político inerente à educação, que marca a impossibilidade de uma prática educativa neutra. Para o autor, a politicidade da educação decorre do pressuposto do inacabamento do sujeito e da história, o qual conduz à necessidade permanente de intervenção ética na "inteligência" dos objetos de conhecimento.

${ }^{5}$ Entendemos por política de significação, com base em Orlandi (1993), o processo de significação constituído na relação tensa entre linguagem e silêncio, pela qual sentidos são afirmados, confrontados ou interditados, determinando, assim, os modos de constituição e representação de sujeitos e sentidos no jogo das formações discursivas.

${ }^{6}$ Conforme Orlandi $(2013$, p. 86), o discurso autoritário é "aquele em que a polissemia é contida, o referente está apagado pela relação de linguagem que se estabelece e o locutor se coloca como agente exclusivo, apagando também sua relação com o interlocutor".
} 
em determinadas formações discursivas $(\mathrm{FD})^{7}$, e produzindo efeitos de despolitização e cristianização do ensino.

Quanto ao discurso do MPCESP, entendemos sua política de significação como o lugar de uma resistência circunscrita à luta ideológica de movimento em torno da educação. Nessa luta, o discurso do MPCESP resiste à política de asfixia do MESP, produzindo choques de deslocamento que reinscrevem o imaginário educacional no campo do político. Chegamos, assim, à definição do que propomos chamar de Política de Resistência do MPCESP: um processo discursivo que trabalha de modo a conter a Política de Asfixia do MESP, produzindo pontos de resistência aos efeitos de despolitização da educação.

Partindo dessas hipóteses de funcionamento discursivo, buscamos, neste artigo, compreender os processos de asfixia e resistência que caracterizam as políticas de significação em confronto. Para tanto, consideramos as questões da relação escolafamília e da abordagem pedagógica de temáticas como gênero e sexualidade, temas amplamente mobilizados nos discursos em análise.

\section{Asfixia da educação: o que (não) pode/deve ser ensinado}

Propomos pensar a asfixia dos objetos de ensino no discurso do MESP como um processo discursivo de despolitização e cristianização do processo de ensinoaprendizagem a partir dos efeitos de interdição/censura de abordagens pedagógicas que problematizam questões concernentes às esferas políticas e socioculturais, bem como efeitos de restrição/redução dos sentidos sobre o que pode e deve ser ensinado na escola. Tais efeitos inscrevem o discurso sob análise em uma política de silenciamento (ORLANDI, 1993) que sufoca a possibilidade de significação em sala de aula, despolitizando, assim, os objetos de conhecimento escolar.

\footnotetext{
${ }^{7}$ A Formação Discursiva, segundo Pêcheux (1975 [2014, p. 147]), é definida como uma rede móvel de sentidos que, "a partir de uma posição dada numa conjuntura dada, [...] determina o que pode e deve ser dito". É pela inscrição em determinada formação discursiva que os sujeitos e sentidos significam.
} 
Iniciemos a análise com a Sequência Discursiva (SD) 1, que materializa a fala de Miguel Nagib, fundador e coordenador do MESP, em audiência pública promovida pela Comissão de Educação da Câmara dos Deputados em junho de 2017.

SD1: Quando, por exemplo, o currículo, ou um professor, por sua própria iniciativa, utiliza seu cargo e o espaço da sala de aula para defender que ninguém nasce homem... e que as pessoas se tornam... nem homem, nem mulher... e isso é uma construção cultural [...] e dessa premissa decorrem outras consequências de natureza moral, de natureza moral. E consequências, conclusões que se chocam com alguns princípios fundamentais da moralidade cristã. Então, ao promover esta visão dentro do sistema educacional, o Estado está deixando de ser neutro em relação à moralidade cristã e, portanto, está ferindo o princípio da laicidade do Estado que é um princípio constitucional (NAGIB, 2017a).

A SD1 recupera a reivindicação do MESP pela neutralidade do Estado no que se refere à educação. Destacamos aqui um funcionamento que marca uma relação contraditória entre laicidade e religiosidade, uma vez que, sob o pretexto de garantia da neutralidade, submete-se a Educação ao ponto de vista da moral cristã, justificando assim a censura à temática da identidade de gênero.

Convém ressaltar que o princípio da laicidade instaura a separação entre Estado e religião, de modo que os diferentes credos não interfiram na política/administração do país. O que ocorre na SD1, no entanto, é a produção de um efeito de distorção desse princípio, como é possível observar no trecho "ao promover esta visão dentro do sistema educacional, o Estado está deixando de ser neutro em relação à moralidade cristã e, portanto, está ferindo o princípio da laicidade do Estado". Produz-se, nessa formulação, um deslizamento de sentido do significante "laicidade": de indiferença do Estado em relação à religião (neutralidade), desliza-se para reverência (subordinação) a valores morais religiosos. Assim, converte-se a ausência da religião na escola em presença necessária. Eis o efeito ideológico fundamental do discurso mespiano: a conversão da educação em religião; do conhecimento em dogma ou valor moral, sob a evidência da reivindicação por neutralidade.

A exigência de um ensino neutro, desse modo, funciona como mecanismo de silenciamento das questões de gênero na escola. Verifica-se, assim, uma tomada de posição do MESP pela moralidade cristã ${ }^{8}$, produzindo o efeito de primazia do religioso

8 Entendemos a moral como um conjunto de saberes de determinada formação discursiva, produzindo um efeito de universalidade para os sujeitos e os sentidos. Por isso, a moral "expressa a tentativa de manter o mesmo, o desejável, e conter o diferente, o indesejável” (GRANTHAM, 1999, p. 213). Com relação às questões de gênero e sexualidade, há, no interior da Formação Discursiva 
sobre o laico, embora no plano da evidência, a laicidade esteja sendo reivindicada. Os objetos de ensino, desse modo, ficam representados como lugares de repetibilidade de normas universais religiosas ligadas à heteronormatividade, impondo ao discurso escolar um lugar único para se falar de determinados temas. Há assim um processo de despolitização e cristianização do processo educacional, num movimento que subverte o princípio da laicidade.

A pretensão do MESP de subordinar a educação à moral familiar/religiosa, mediante interdição de certos temas, também pode ser observada no modo como o movimento aborda a questão da homofobia, como podemos observar na SD2, recortada de uma entrevista feita com Miguel Nagib para o portal eletrônico HuffPost Brasil:

SD2: O Estado pode fazer uma política contra homofobia usando os meios de comunicação. O Estado tem uma verba bilionária para isso. Ele vai fazer propaganda na televisão porque ninguém é obrigado a assistir essas propagandas. Na sala de aula é diferente porque o pai é obrigado a colocar o filho na escola (NAGIB, 2017b).

A interdição à temática da homofobia na escola emerge na SD2 a partir de um efeito de desresponsabilização da escola frente a problemáticas sociais. Ao definir que os meios de comunicação constituem o espaço adequado para a divulgação de políticas contra a homofobia porque ninguém é obrigado a assistir, o discurso do movimento acaba por restringir o combate à homofobia a uma questão opcional. Este efeito de desresponsabilização fica mais evidente quando se considera que o Plano Nacional de Educação (PNE) tem como meta a "superação das desigualdades educacionais, com ênfase na promoção da cidadania e na erradicação de todas as formas de discriminação" (BRASIL, 2017, p. 32).

O efeito de desresponsabilização da escola no combate à discriminação traz à tona um outro, o de supremacia de objetos de ensino que contemplem saberes técnicos, pondo em evidência uma concepção de educação enquanto instrução, a serviço da conservação/reprodução da estrutura social. É o que se pode observar a partir da $\mathrm{SD}_{3}$ :

Cristã, a determinação moral de que o gênero é definido pelo sexo biológico e que a única configuração legítima para as relações afetivas e sexuais é o par homem e mulher. Qualquer outra forma de existência do sujeito que se insurja a essa ordem é considerada pecaminosa, passível de punição. Por essa razão, a ideia de aceitação da diversidade de gênero é interditada no interior da FD Cristã, e, portanto, censurada no discurso mespiano. 
SD3: [...] essa nefasta ideologia de gênero, esse lixo que atrasa o Brasil e que faz as nossas crianças aqui emburrecerem porque enquanto aqui a gente fica aprendendo esse tipo de besteira, na Coreia do Norte, no Japão, os alunos lá estão com doze anos de idade, fazendo contas que os nossos universitários não fazem. Então, senhor presidente, temos, sim, que aprovar essa lei, colocála adiante pra acabar com esse tipo de besteira e ensinar que na escola é lugar de aprender matemática, física, biologia para que sejam bons profissionais e boas pessoas em suas casas porque uma família que não tem problema, ela é rentável ao Estado (BOLSONARO, 2016).

$\mathrm{A} \mathrm{SD}_{3}$ foi recortada de uma fala do deputado federal do estado de São Paulo, Eduardo Bolsonaro, em uma Comissão de Educação, realizada na Câmara dos Deputados. As formulações dessa SD colocam em jogo uma suposta divisão entre conteúdos ideológicos e conteúdos neutros, a qual redunda num processo de restrição/redução dos sentidos dos objetos de ensino e numa concepção de escola como lugar de instrução de conteúdos "não ideologizados", isto é, conteúdos técnicos, imaginariamente estáveis, transparentes e neutros. Note-se que a $\mathrm{SD}_{3}$ reforça o efeito de deslegitimação produzido na SDı quanto à abordagem pedagógica dos estudos de gênero, definida agora como ideologia de gênero, "nefasta", "lixo" e "besteira"; por outro lado, legitima os objetos de ensino ligados ao campo profissional-técnico. Com isso, contorna-se o caráter material do sentido e, portanto, dos objetos de conhecimento que, como observa Pêcheux (1990), se inscrevem em espaços discursivos não logicamente estabilizados, dando margem a interpretações divergentes ou contraditórias. Nessa perspectiva, a polissemia do processo de ensino-aprendizagem é sufocada pela instrução.

Diante do que precede, podemos postular a filiação da $\mathrm{SD}_{3}$ a uma $\mathrm{FD}$ neoliberal da educação, que significa o processo de ensino-aprendizagem como reprodutor das relações de produção capitalistas. O vestígio dessa filiação está nas expressões "bons profissionais" e "rentáveis para o Estado", que representam a escola como lugar de formação de profissionais bem adaptados às relações de trabalho/exploração capitalistas, das quais o Estado é parceiro. Por essa razão, na SD3, o tratamento pedagógico de temas como gênero e orientação sexual figura como um desfalque na educação, por não ser um conteúdo "neutro", nem técnico e, portanto, não rentável, emburrecendo os alunos e atrasando o Brasil.

As três SD analisadas ilustram, ainda que brevemente, o modo de funcionamento da política de asfixia do MESP, permitindo-nos observar o trabalho de 
um silenciamento (ORLANDI, 1993) de ordem moral, que sufoca o caráter político do ensino, na medida em que busca evitar a abordagem de objetos de conhecimento polêmicos, a exemplo das questões de gênero e sexualidade. O efeito produzido é o de um ensino enquanto instrução, onde os objetos de conhecimento são representados como conteúdos neutros, estanques, sem possibilidade de equívoco e deslocamentos.

\section{Resistência à asfixia da educação: o que (não) pode/deve ser ensinado}

A resistência, sob uma perspectiva discursiva, é pensada como possibilidade de ruptura, de deslocamentos produzidos nos furos e falhas da ideologia dominante, através da tomada da palavra, da produção do sentido outro. Assim sendo, alerta Pêcheux (1982 [1990]) que a resistência não está centrada na vontade de um sujeito ou de um grupo sócio-histórico que, fora da ideologia, buscaria combatê-la. O autor descarta, ainda, a concepção de que a resistência pressupõe o confronto de dois mundos diferentes, como se as ideologias dominadas tivessem uma ideologia distinta e independente.

Pelo contrário, a resistência é produzida, contraditoriamente, no interior da ideologia dominante, podendo oferecer aos sujeitos a possibilidade de despedirem-se "do sentido que reproduz o discurso da dominação, de modo que o irrealizado advenha formando sentido do interior do sem-sentido" (PÊCHEUX, 1982 [1990, p. 17]). Desse modo, a resistência se constitui pela contradição e pelo equívoco, surgindo na reprodução ideológica, no momento em que o ritual se estilhaça.

Pensamos, pois, na Política de Resistência do MPCESP como aquela capaz de produzir choques de deslocamento que irrompem nos furos e falhas da Política de Asfixia, de modo a resistir àquilo que se apresenta como saturado no discurso do MESP: um ensino neutro, limitado à instrução.

Nas três sequências que compõem este recorte analítico, é possível evidenciar no discurso do MPCESP a produção de deslocamentos que marcam gestos de resistência, materializados por efeitos de 1) denúncia à despolitização do ensino e 2) 
reiteração dos sentidos que evidenciam o caráter político da educação. Vejamos como esses efeitos são produzidos, iniciando com a SD4.

SD4: O movimento Escola sem Partido confunde propositalmente política com política partidária, desconhecendo que não se faz educação sem dimensão política e que discutir aspectos como sustentabilidade, igualdade de gênero, diversidade de orientações sexuais, entre outros pontos combatidos pelo movimento, não constitui doutrinação partidária. Ao limitar a discussão em sala de aula acerca da diversidade de ideias, valores e atitudes existente na sociedade brasileira, o movimento Escola sem Partido e os PLs por ele patrocinados, embora sejam supostamente contrários à doutrinação, constituem, na verdade, uma forma particularmente violenta de doutrinação que atinge nossas escolas, mina a possibilidade de um trabalho docente de qualidade e esvazia a educação de sua função social ${ }^{9}$.

Logo de início, chamamos atenção para o fato de que, por se constituir enquanto um contradiscurso, o dizer do MPCESP é marcado pela regularidade de evocar a presença de seu opositor, realçando a posição daquele contra quem se luta (PÊCHEUX; WESSELIUS, 1973 [1977]). Nessa retomada do discurso antagônico, é possível observar o funcionamento da resistência na produção de um deslocamento que faz derivar o sentido de doutrinação construído pelo MESP. Como nos fala Pêcheux (1982 [1990, p. 17]), o gesto de "mudar, desviar, alterar o sentido das palavras e das frases" constitui um modo de resistir.

Na SD4, o ato de discutir aspectos como sustentabilidade, igualdade de gênero, diversidade de orientações sexuais não constitui doutrinação partidária, do contrário: essas temáticas são defendidas como aquilo que pode/deve ser ensinado, uma vez que abarcam a dimensão política, destacada como critério para que haja educação: não se faz educação sem dimensão política. Realçamos, aqui, o funcionamento da negação que, conforme Lagazzi-Rodrigues (1999, p. 129), "produz diferentes lugares discursivos, diferentes posições de sujeito, diferentes fatos". Nesse sentido, assumimos que a negação possui um duplo funcionamento no qual produz-se uma posição, rejeitando outras. A estrutura negativa, desse modo, funciona nessa formulação num movimento

\footnotetext{
${ }^{9}$ Moção de repúdio ao PL Escola sem Partido elaborada em Assembleia Geral Ordinária, durante o X Encontro de Pesquisa em Educação em Ciências (ENPEC), no dia 26/11/2015 pela Associação Brasileira de Pesquisa em Educação em Ciências (ABRAPEC) e a Associação Brasileira de Ensino de Biologia (SBEnBio). Disponível em: http://abrapecnet.org.br/wordpress/wpcontent/uploads/2015/12/Escola-sem-partido.pdf.
} 
de mão dupla, que resiste à despolitização dos objetos de ensino, reafirmando, ao mesmo tempo, seu caráter político.

Por outro lado, a prática doutrinária é designada, na $\mathrm{SD}_{4}$, como o ato de limitar a discussão em sala de aula acerca da diversidade de ideias, valores e atitudes existentes na sociedade brasileira. Nesse deslocamento, produz-se uma inversão que marca outro ponto de resistência: aqui, o agente doutrinador não é o professor/escola, mas o MESP, por conter a diversidade (de ideias, valores e atitudes), refreando, em consequência, o sentido outro.

Evidencia-se, assim, uma tomada de posição que produz um imaginário de educação política, aberta à polissemia dos sujeitos e dos sentidos, conforme se pode observar na $\mathrm{SD}_{5}$.

SD5: Nós da Frente Goiana pela Escola sem Mordaça, formada por sindicatos de trabalhadores da educação, movimentos sociais e coletivos de luta, defendemos que a educação e a escola devem formar cidadãos através do debate sobre diversidades culturais, de gênero e sexualidade, além de questões políticas e sociais. A Lei da Mordaça quer na verdade impedir a livre organização social, ameaçando o próprio direito constitucional de liberdade, pensamento e expressão, bem como eliminando a autonomia de trabalho do professor $^{10}$.

Lembra-nos Grigoletto e De Nardi (2016, p. 280) que "toda tomada de posição implica um gesto de resistência", tendo em vista que, ao se identificar com determinada posição, os sujeitos e os sentidos, necessariamente, resistem a tantas outras. Nessa tomada de posição, o MPCESP resiste à posição do MESP, marcando para si um lugar autointitulado contrário ao Escola sem Partido. Note-se que a própria autodesignação da Frente evidencia uma resistência produzida pelo efeito de antagonismo entre um nós, a Escola sem Mordaça, e um ela, a Lei da Mordaça, ou a Escola com Mordaça, fazendo referência ao MESP. É importante salientar que a última formulação permite observar um deslocamento produzido por um efeito metafórico (PÊCHEUX, 1975 [2014]): de Escola sem partido, desliza-se para Escola com Mordaça. Uma palavra por outra, um gesto de resistência.

Ainda sobre o nós, que marca a posição do MPCESP, destacamos que ele assume a função de representar o movimento como inscrito no mesmo espaço de resistência

\footnotetext{
${ }^{10}$ Manifesto de repúdio à Lei da Mordaça, Frente Goiana por uma Escola sem Mordaça. Disponível em: http://sintef.org.br/wp/wp-content/uploads/2016/08/Manifesto-de-Rep\%C3\%BAdio-\%C3\%A0-leida-morda\%C3\%A7a.pdf.
} 
de grupos sociais marcados por uma memória de luta e militância política, como sindicatos, trabalhadores da educação, movimentos sociais e coletivos. Desse lugar de resistência, o discurso do MPCESP reitera do caráter político da educação, definindo como objetos de ensino necessários à formação cidadã o debate sobre diversidades culturais, de gênero e sexualidade, além de questões políticas e sociais.

Outro aspecto importante a se destacar no discurso do MPCESP é o gesto de resistência produzido pelo efeito de denúncia, introduzido pelo uso da locução adverbial "na verdade", que funciona de modo a denunciar, isto é, "anunciar, propagar, dizer (a verdade)" (PAYER, 2006, p. 64) sobre o "real propósito" do MESP que, segundo o movimento, seria o de "impedir a livre organização social; ameaçar os direitos constitucionais da liberdade, pensamento e expressão; e eliminar a autonomia do professor".

Os verbos em destaque que (d)enunciam, imaginariamente, a "verdade" sobre o MESP fazem referência a ações coercitivas de censura (impedir, ameaçar e eliminar), uma censura que, conforme formulado na $\mathrm{SD}_{5}$, impõe-se à livre organização social, aos direitos de liberdade, pensamento e expressão. A própria designação "Lei da Mordaça”, fazendo referência aos Projetos de Lei Escola sem Partido, evidencia uma escolha lexical que produz esse efeito da denúncia de que há, nos PL, uma tentativa de amordaçar, isto é, censurar os professores, bem como a função política e social do processo de ensino-aprendizagem. Em contraposição a essa censura, o movimento toma para si o título de Escola sem Mordaça, marcando outro deslizamento (com mordaça > sem mordaça) que reafirma sua posição de resistência.

Na SD6, a resistência à asfixia dos objetos de ensino se realiza a partir de um deslocamento dos sentidos produzidos pelo MESP, referentes à imposição da moral familiar sobre aquilo que pode/deve ser ensinado. Nesse deslocamento, o MPCESP representa os objetos de ensino enquanto elementos não subordinados às convicções familiares, mas às demandas sociais.

SD6: Se uma família não aceitar a justiça social, por exemplo, não considero justo e adequado a moral familiar se sobrepor à missão da educação escolar. Se a família tiver uma postura discriminatória, por exemplo, a moral familiar deve ser enfrentada e não pode se sobrepor à educação escolar. A família precisa ser considerada como parte da sociedade. Mas não pode ser maior do que o todo (CARA, 2018). 
A SD6 recorta uma matéria publicada no site do Centro de Referência em Educação Integral, que apresenta o posicionamento de educadores sobre os Projetos de Lei Escola sem Partido. Dentre os educadores entrevistados, está o coordenador geral da Campanha Nacional pelo Direito à Educação, Daniel Cara, que, em seu dizer, traz à tona a problemática sobre a relação família-escola, em especial, a questão da moral familiar impondo-se no contexto educacional.

O deslocamento ao qual nos referimos pode ser observado na SD6 a partir da problematização levantada sobre o papel da família na educação escolar. Em oposição ao que é projetado no discurso mespiano, a família é destituída do lugar de autoridade inquestionável e é (re)inscrita no espaço público como parte da sociedade. Nessa perspectiva, a SD6 produz o efeito de soberania da escola em referência às convicções familiares (a moral familiar não pode se sobrepor à educação escolar). Marca-se, portanto, um movimento contrário ao observado na análise da SD1, a respeito da reverência à moral familiar, reafirmando-se a indiferença aos particularismos religiosos, o que remete ao princípio da laicidade.

A resistência à asfixia dos objetos de ensino, assim, irrompe no discurso do MPCESP por meio de gestos de resistência que reinscrevem a educação no campo do político, produzindo um efeito de laicização dos objetos de ensino, em contraposição à cristianização desses.

\section{Entre a asfixia e a resistência: efeitos e desdobramentos}

Nessa breve reflexão que empreendemos, o batimento entre descrição e interpretação nos possibilitou contribuir com a compreensão do modo como as discursividades do MESP e do MPCESP se inscrevem na luta ideológica de movimento em torno da educação nacional. De um lado, pudemos observar, no discurso do MESP, movimentos de asfixia produzidos pela interdição de sentidos que polemizam o espaço escolar, como os da sexualidade e das identidades de gênero. Observamos, também, efeitos de restrição/redução dos sentidos sobre o que se pode/deve ensinar na escola, 
limitando-os a conteúdos de saberes técnicos, imaginariamente neutros e transparentes.

Nossas análises puderam evidenciar o fato de que, ao contrário do que se apregoa pelo MESP, a escola por eles defendida, dita "sem partido", é uma escola que toma partido em favor da cristianização e mercantilização da educação. Essa posição ideológica, no entanto, é esfumada pelo apelo à neutralidade, que funciona como uma estratégia discursiva de direção política da educação, de sua partidarização.

Entendemos que o ensino "neutro" defendido pelo MESP figura como um instrumento de domesticação dos aprendizes para a manutenção da estrutura social, baseada nos princípios patriarcais/religiosos e nas relações de trabalho/exploração capitalistas. Sob essa perspectiva, constrói-se um imaginário educacional para a submissão e conformismo, e, portanto, para a perpetuação do status quo.

Por outro lado, pudemos observar, no discurso do MPCESP, gestos de resistência à asfixia, isto é, deslocamentos que produzem efeitos de denúncia à despolitização do ensino pretendida pelo MESP, bem como efeitos de laicização e reafirmação do papel político do processo de ensino-aprendizagem.

A discursividade do MPCESP se inscreve numa rede de memória do ensino crítico, gestado como meio de "proporcionar aos estudantes habilidades e informações necessárias para pensarem criticamente sobre o conhecimento que adquirem e sobre o que pode significar para eles desafiar formas antidemocráticas de poder" (GIROUX, 2003, p. 21). Sob esse prisma, a educação é pensada como possibilidade de transformação social, ruptura, resistência à ideologia já-lá.

Desse modo, na conjuntura atual, entre a asfixia e a resistência, o discurso político-educacional tem sido tensionado na/pela linguagem, dividindo-se em dois possíveis horizontes: de um lado, a emergência daquilo que podemos chamar de narcisia social (ORLANDI, 1993), isto é, rarefação do sentido, imposição/perpetuação de um sentido único para a sociedade, calcado na moral religiosa e na lógica capitalista; de outro, politicidade, polissemia, abertura dos sentidos à contradição, sob um ponto de vista laico da formação social.

Tendo em vista tais horizontes, é urgente que professores e analistas estejam atentos aos desdobramentos dessa luta ideológica, resistindo e produzindo leituras 
críticas que contribuam para o fortalecimento e defesa de uma educação laica, plural e democrática.

\section{Referências}

BRASIL. Lei n.13.005, de 25 de junho de 2014. Aprova o Plano Nacional de Educação PNE e dá outras providências. Diário Oficial da União, Brasília, DF., 26 jun 2014. Disponível em: <https://www.planalto.gov.br/ccivil_03/_ ato2011-2014/2014/lei/l13005.htm>.

BOLSONARO, E. Canal Fabio Iwamoto. Vídeo "Eduardo Bolsonaro critica doutrinação da Comissão de Educação". YouTube, 02 de mai de 2016. Disponível em: <https://www.youtube.com/watch?v=A4dY_DtZRZg>. Acesso em: 23 de abr de 2018.

CARA, D. "Por que o Escola Sem Partido vai contra o papel da escola". Educação Integral, 24 mai. 2018. Disponível em: <http://educacaointegral.org.br/reportagens/por-que-o-escola-sem-partido-vaicontra-o-papel-da-escola/>. Acesso em 28 de maio de 2018.

FREIRE, P. Pedagogia da autonomia: saberes necessários à prática educativa. São Paulo: Paz e Terra, 1996.

GIROUX, H. A. Atos impuros: a prática política dos estudos culturais. Porto Alegre: Artmed, 2003.

GRANTHAM, M. A moral e a ordem do repetível. In: INDURSKY, F. FERREIRA, M. L. (Org.). Os múltiplos territórios da análise do discurso. Porto Alegre: Editora Sagra, 1999. p. 216-229.

GRIGOLETTO, E; DE NARDI, F. (Des)politização e resistência no funcionamento dos processos de heroicização construídos pelo discurso da mídia. In: . (Org). Análise do discurso e sua história: avanços e perspectivas. Campinas, SP: Pontes Editores, 2016.

LAGAZZI-RODRIGUES, S. A negação no discurso político eleitoral: impossibilidade e inaceitabilidade. In: INDURSKY, F. FERREIRA, M. C. L. (Org.). Os múltiplos territórios da análise do discurso. Porto Alegre: Editora Sagra, 1999. p. 122-130. 
NAGIB, M. Canal Verdade Política. Vídeo "Miguel Nagib adverte sobre a ideologia de gênero". YouTube, 13 de jun de 2017a. Disponível em: <https://www.youtube.com/watch?v=t3qdyJ7VSB4>. Acesso em: 22 de out de 2017.

. "Homofobia não é assunto de sala de aula, defende fundador da Escola sem

Partido".

HuffPost Brasil, 24 fev. 2017b. Disponível em: <https://www.huffpostbrasil.com/2017/o 2/24/homofobia-nao-e-assunto-de-sala-de-aula-defende-fundador-da-es_a_21721269/>. Acesso em o5 de janeiro de 2018.

ORLANDI, E. As formas do silêncio: no movimento dos sentidos. 2. ed. Campinas, SP: Ed. Unicamp, 1993.

Análise de Discurso: princípios e procedimentos. 11. ed. Campinas, SP:

Pontes, 2013.

ORLANDI, E. Discurso em análise: sujeito, sentido e ideologia. Campinas: Pontes Editores, 2016.

PAYER, M. O. Escrever, (d)enunciar a verdade, sugerir sentidos. In: MARIANI, B. (org.). A escrita e os escritos: reflexões em análise do discurso e em psicanálise. São Carlos: Claraluz, 2006, p. 59-70.

PÊCHEUX, M; WESSELIUS, J. A respeito do movimento estudantil e das lutas da classe operária: três organizações estudantis em 1968. In: ROBIN, Régine. História e linguística. São Paulo: Cultrix, 1977 [1973]. p. 265-282.

PÊCHEUX, M. A língua inatingível. In: ORLANDI, Eni. (Org.) Análise de discurso: Michel Pêcheux - textos escolhidos por Eni Orlandi. Campinas: Pontes Editores, [1982] 2014, p. 93-105.

. O discurso: estrutura ou acontecimento. Campinas: Pontes Editores, 1990.

. Semântica e discurso. Uma crítica à afirmação do óbvio. Campinas, SP: Ed. Unicamp, [1975] 2014.

. Delimitações, inversões, deslocamentos. In: Caderno de estudos linguístico, n 19, Campinas: Unicamp, [1990] 1982, p. 07-24.

SINGER, A. As democracias passam por um momento muito difícil. São Paulo: Ipea: desafios do desenvolvimento, 28 mar. 2016. Disponível em: <http://www.ipea.gov.br/desafios/index.php?option=com_content\&view=article\&id=3 231\&catid=30>. Acesso em: 20 fev. de 2018. 
UNIVERSIDADE DO ESTADO DO RIO DE JANEIRO. Notícias do portal. Moção contra o Programa Escola sem Partido. Publicado em o3 de ago. de 2016. Disponível em: <http://www.uerj.br/lendo_noticia.php?id=1051>. Acesso em: 20 de nov. de 2016.

Recebido em 17/09/2018.

Aprovado em 03/11/2018. 